\title{
Measuring our investment in the future
}

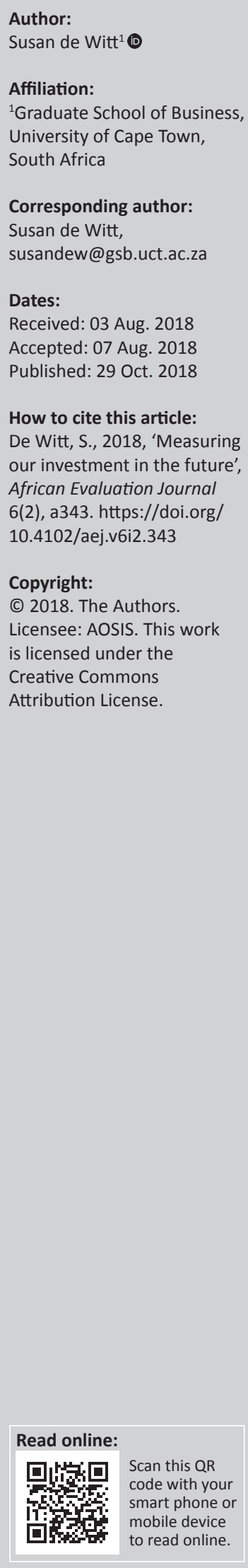

Global consensus has been built around a few key issues, and there have been a slew of unifying declarations and commitments as a result. The climate is changing and those countries in the Paris Accord have committed to reducing carbon output in an attempt to slow it down. The world is inequitable and unstable, and those countries signed up to the United Nations Sustainable Development Goals have identified 17 areas in which we need to address global development. It is also becoming clearer to the person on the street that capital markets are not as effective at allocating risk as believed and this is putting everyone in danger. The financial crises over the last few decades are examples of how large miscalculations affect billions of lives, especially those who are most vulnerable to begin with.

Global consensus has been built around a few key issues and, as a result, there have been a slew of unifying declarations and commitments. The climate is changing and those countries in the Paris Accord have committed to reducing carbon output in an attempt to slow it down. The world is inequitable and unstable, and those countries signed up to the United Nations Sustainable Development Goals (SDGs) have identified 17 areas in which we need to address global development. It is also becoming clearer to the person on the street that capital markets are not as effective at allocating risk as believed and this is putting everyone in danger. The financial crises over the last few decades are examples of how large miscalculations affect billions of lives, especially those who are most vulnerable to begin with.

As the term was first coined by a group of investors in 2007, there has been a running debate as to whether 'impact investing' should be developed as a separate asset class or whether it should cut across asset classes. It is now widely accepted that all organisations and investments generate either a net positive or a net negative impact. Impact investing seeks to encourage and enable the market to price the positive and negative externalities into the price of goods and services, thus an 'impact lens' is applied across the financial sector alongside the current financial performance metrics of risk, return and liquidity. However, the elevation of impact into the performance metrics of financial investments will only be able to happen with the robust support of the impact measurement community, so that it is possible to rigorously and objectively measure impact consistently and confidently.

Currently, 26\% or $\$ 23$ trillion of the world's financial markets are allocated to responsible investment (Global Sustainable Investment Alliance 2016). The majority of those investors apply a negative screen to their portfolios cutting out things such as tobacco, pornography, nuclear weapons and, more recently, fossil fuels. A smaller percentage is driving sustainable finance where environmental, social and governance screens are applied to companies to reduce longterm risk. In fact, the United Nations Principles for Responsible Investment are championing the integration of Environment Social Governance (ESG) scores into company valuations particularly for equity investments (UN Principles for Responsible Investment [UNPRI] 2016). There is evidence to suggest that this type of integration leads to improved financial performance over the long term. And lastly, there is a group of investors who are specifically seeking to finance businesses and projects that create goods and services that directly address the SDGs. These are commonly known as impact investors.

So, whilst we should be moving to a point where all companies will need to price their net impact, for the time being we are focusing on companies that seek to benefit people and planet, which includes funding solutions to intractable social and environmental problems.

The question is how are we doing this and what are some of the major bottlenecks that need to be addressed so that money can move at scale? Although the market is predicted to more than 
double in size from $\$ 114$ to $\$ 300$ billion by 2020 , this is insignificant in comparison to the estimated capital gap of $\$ 50$ - \$70 trillion needed to achieve the SDGs by 2030 (Mudaliar, Bass \& Dithrich 2018). There is a palpable sense of urgency across the globe to accelerate the growth of the supply and demand sides of the market using cross country and sector consensus building. There are a considerable number of asset holders and managers busily identifying investable opportunities, many of whom will move quickly to fill them. For example, PGGM, a Dutch asset manager with $€ 220$ million pension fund money under management, has mapped their impact using the Impact Management Convention (Impact Management Project 2017) and published a taxonomy of SDG-linked investment areas (PGGM \& APG 2017) and is now reorienting their portfolio to match their impact goals.

How can others follow in the footsteps of these pioneers in a market that still rewards short-term shareholder returns? Innovative finance is an approach to funding enterprises and interventions that optimises positive social, environmental and financial impact. It uses all available financial and philanthropic tools to support the growth of enterprises, interventions and entrepreneurs, and when existing tools are inappropriate and ineffective, new tools are created to enable the investment (Bertha Centre for Social Innovation and Entrepreneurship 2017).

It is clear from the size of the market that there are big blockages to address in order to finance and grow the kinds of organisations that can fill these development gaps. Firstly, there is a mismatch between the type of capital needed and the type of capital available. The venture capital model making daily headlines out of Silicon Valley is not necessarily suitable for the type of business models that are addressing longer term education or health needs, for instance. Venture capital seeking high returns and quick exits does not immediately fit within an African context where entrepreneurs are less willing to sell ownership of their companies in order for investors to cash in on lucrative exits. On a continent where markets are less crowded, it is not the fast growing 'gazelles' that need support, but often rather the slower growing businesses that grow organically and sustainably. These are termed the 'oxen' in less sexy industries that make up the backbone of the economy and often only require periodic injections of working capital in the form of unsecured loans. The cohort of Enterprise Supplier Development Funds emanating from South Africa's Black Economic Empowerment legislation is a perfect example of how the non-bank financial sector is plugging a gap.

Across the market, we are seeing traditional instruments being tweaked to better meet the needs of end users. One of those is 'Fintech' and not least because of the cryptocurrencymania that has gripped the world. It is yet to be seen how alternative currencies will disrupt banking at large but this phenomenon is a significant step towards democratising capital. 'Alternative credit scoring' is showing immediate effect at the bottom of the pyramid to reach the unbanked as developed by FICO, CreditVisonLink and Cignifi amongst others. As technology advances, these microcredit transactions are accelerating as facilitated by big data sets from mobile phone records and social media interactions to assess default risk. More people are getting access to finance through these innovative methodologies, many of which rely on the expertise of data analytics, one of the core competencies of the impact measurement sector.

Instead of simply measuring impact as part of the due diligence or exit calculation, businesses and investors need to and are starting to include ongoing impact measurement into business strategy and portfolio management decisions. The opportunities afforded by emerging business models associated with the Global Goals are plentiful and profitable, not only in the more established sectors such as affordable housing, low-cost private schooling renewable energy and agribusiness but also in new areas such as sustainable aquaculture, car sharing, circular models of electronics and low-cost surgery (Business and Sustainable Development Commission 2017). Best in class ESG frameworks such as Global Reporting Initiative and the UNPRI, impact metrics such as IRIS of the Global Impact Investing Network (GIIN) and BLab and conventions such as the Impact Management Project are gaining traction as consolidation and standardisation become essential strategies in building the case for pricing in impact.

The impact measurement community is starting to organise as their role evolves from being evaluation specialists to leading the charge in finding value in investment. In other words, we are starting to work out how much extra value is actually being created by using these business models, and fund managers are taking notice. They are starting to take notice not only because they can invest in untapped markets but also so that they can generate 'impact alpha' for their investors. Impact alpha refers to the return over and above what they would otherwise achieve in a benchmark index. There are more and more examples of how private equity and fixed-income portfolios are producing results commensurate with the market and often times beating the market especially during market downturns (Mudaliar \& Bass 2017).

Ultimately, what most people want is a world that is sustainable for future generations - for our children and our children's children. This means protecting the environment from further degradation and ensuring that all communities are included in the economy and afforded the opportunity of prospering. If we are going to meet the SDGs, it is the poor and marginalised that require a greater share of the world's resources.

\section{Acknowledgements Competing interests}

The author declares that she has no financial or personal relationships that may have inappropriately influenced her in writing this article. 


\section{References}

Bertha Centre for Social Innovation and Entrepreneurship, 2017, Innovative finance in Africa review, viewed n.d., from http://www.gsb.uct.ac.za/innovative-financeafrica-review

Business and Sustainable Development Commission, 2017, Better business better world, viewed n.d., from http://report.businesscommission.org/report

Business \& Sustainable Development Commission, \& Convergence, 2017, The state of blended finance, viewed n.d., from http://s3.amazonaws.com/aws-bsdc/BSDC and_Convergence_The_State_of_Blended_Finance_July_2017.pdf

Global Sustainable Investment Alliance, 2016, Global sustainable investment review, viewed n.d. from http://www.gsi-alliance.org/wp-content/uploads/2017/03/ GSIR_Review2016.F.pdf
Impact Management Project, 2017, The Investors's perspective: PGGM, viewed n.d., from http://www.impactmanagementproject.com/wp-content/uploads/2018/01/ Investor-Perspective_PGGM_re-release-1.pdf

Mudaliar, A. \& Bass, R., 2017, GIIN Perspectives: Evidence on the financial performance of impact investments, viewed n.d., from https://thegiin.org/research/publication/ financial-performance

Mudaliar, A., Bass, R. \& Dithrich, H., 2018, Annual Impact Investor Survey 2018, viewed n.d., from https://thegiin.org/research/publication/annualsurvey2018

PGGM \& APG, 2017, Sustainable development investments (SDIs), viewed n.d., from https://www.pggm.nl/english/what-we-do/Documents/SDI-taxonomies-APG PGGM-mei_2017.pdf

UN Principles for Responsible Investment (UNPRI), 2016, A practical guide to ESG integration for equity investing, viewed n.d., from https://www.unpri.org/listedequity/a-practical-guide-to-esg-integration-for-equity-investing/10.article 